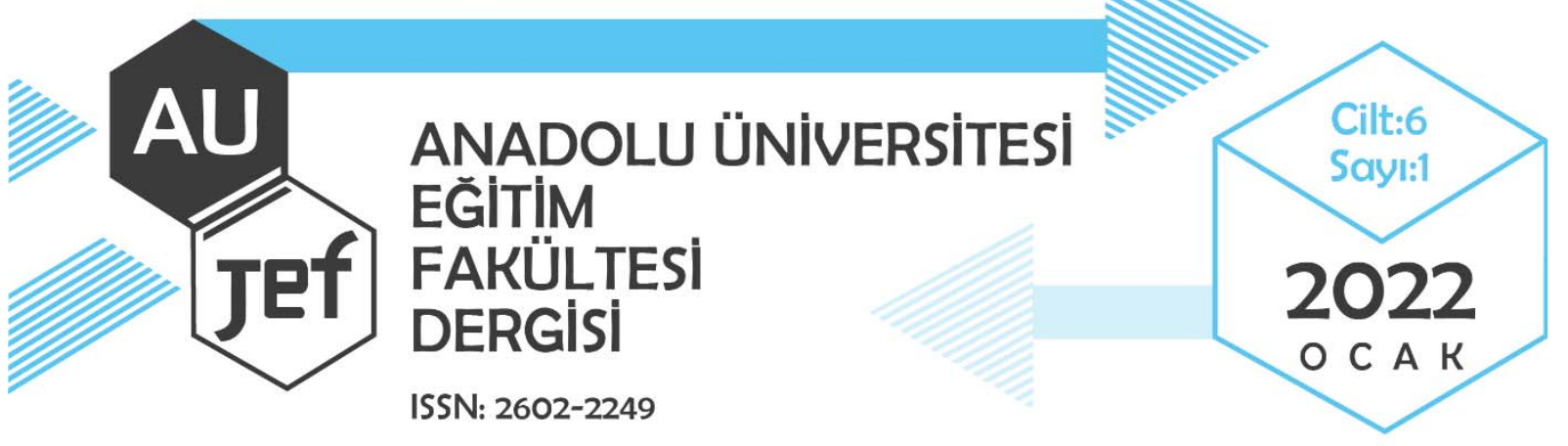

\title{
Gülten Dayıoğlu Eserlerinde Kalıp Söz Varlığı (Yurdumu Özledim ve Tuna’dan Uçan Kuş Örneği)
}

\section{The Presence of Formulaic Words in Gülten Dayığlu's Works (The Example of Yurdumu Özledim and Tuna'dan Uçan Kuş)}

Şükrü ÖZEN ${ }^{1}$

\author{
Makale Türü: Araştırma Makalesi
}

Başvuru Tarihi: 23.04.2021

Kabul Tarihi: 07.12.2021

Atıf İçin: Özen, Ş. (2022). Gülten Dayığlu Eserlerinde Kalıp Söz Varlığı (Yurdumu Özledim ve Tuna'dan Uçan Kuş Örneği). Anadolu Üniversitesi Eğitim Fakültesi Dergisi (AUJEF), 6(1), 1-16.

ÖZ: $\mathrm{Bu}$ çalışma Gülten Dayığlu eserlerindeki kalıp söz varlı̆̆ını kategorik olarak ortaya koymayı amaçlamaktadır. Kalıp sözler iletişimi düzenleyen dil birimleridir. Atasözü, deyim ikileme gibi kalıplaşmış ifadelerden farklı olarak kalıp sözlerin yaşamın her alanında ve anında kullanıldığı bilinmektedir. Bu sebeple günlük hayatta sıkça kullanılan kültürel bir yanı bulunan kalıp sözler her ne kadar Türkçe ders kitaplarındaki bazı metinlerde yer bulsa da kalıp sözlerin MEB Türkçe öğretim müfredatında bir kazanım maddesi olarak yer almaması, kalıp söz ediniminin edebi eserler yoluyla düzenlenmesini ihtiyaç haline getirmektedir. Ortaokul düzeyinde öğrenim gören bireyler için Gülten Dayığlu eserleri, ruhsal ve bilişsel gelişimlerine olduğu kadar kalıp söz dağarcıklarının gelişimine de katkı sunabilir. Bu doğrultuda alan uzmanı 3 Türkçe öğretmeni ve bir Türkçe eğitimi bölümü öğretim üyesinin ortak önerisi olan Gülten Dayığlu'na ait 'Yurdumu Özledim' ve 'Tuna'dan Uçan Kuş’ adlı eserlerdeki kalıp söz varlı̆̆ı, kullanım alanları yönünden kategorik olarak incelenmiştir. Çalışmanın yöntemi betimsel araştırmaya göre desenlenmiş, verileri doküman inceleme yoluyla elde edilmiştir. Ulaşılan veriler içerik analizi ile ele alınıp yorumlanmıştır. Bulguların frekans değerleri tablolar halinde gösterilmiştir. Buna göre eserlerin 'hayır dua ve iyi dilek bildiren', 'duygusal tepkileri dile getiren', 'dini inanç bildiren' kalıp sözler yönünden yeterli olduğu görülmüştür. Her iki eserde de 'batıl inanç bildiren' kalıp sözlere yer verilmediği dikkat çekmektedir. Sonuç olarak eserlerin kalıp sözlerin kategorik olarak belirli durumlarda kullanılmak üzere kazandırılmasında etkili birer kaynak olduğu düşünülmektedir.

Anahtar sözcükler: Gülten Dayığlu, kalıp söz, söz varlığı, Türkçe eğitimi

\begin{abstract}
This study aimed to categorically reveal the presence of formulaic words in Gülten Dayığlu's works. Formulaic words are language units that regulate communication. Unlike stereotypes such as proverbs and idioms, it is known that formulaic words are used in all areas and moments of life. For this reason, the fact that formulaic words, which are frequently used in daily life, are not included in the Turkish education curriculum of the MoNE makes it necessary to organize pattern speech through literary works. For individuals studying at the secondary school level, Gülten Dayığlu's works can contribute to the development of formulaic word vocabulary as well as their spiritual and cognitive development. In this direction, the formulaic words in the works named "Yurdumu Özledim" and "Tuna'dan Uçan Kuş" by Gülten Dayıŏglu, who is a joint
\end{abstract}

\footnotetext{
${ }^{1}$ Uzman, MEB, sukru.ozen@outlook.com, ORCID: 0000-0002-3731-4842
} 
recommendation of 3 Turkish teachers and a Turkish education department lecturer, were categorically examined in terms of usage areas. The study was designed as descriptive research, and the data were obtained through document analysis. The obtained data were handled and interpreted with content analysis. The frequency values of the findings are shown in tables. According to this, the works were found to be sufficient in terms of "expressing blessings and good wishes", "expressing emotional reactions", "expressing religious belief". It is noteworthy that in both works, there is no formulaic word "expressing superstition". As a result, it is thought that the works are an effective source in the acquisition of formulaic words categorically to be used in certain situations.

Keywords: Gülten Dayığlu, formulaic word, vocabulary, Turkish education 


\section{GíRiş}

Dil, insanlık var olduğundan bu yana en etkili iletişim aracı olmuştur. Bireyler duygu ve düşüncelerini önceleri konuşarak ve dinleyerek sonraları ise yazarak ve okuyarak anlatmış ve anlamıştır. Böylelikle dil insanların toplum haline gelmesindeki en önemli unsur olmuştur (Aksan, 2007, s.12). Toplum haline gelen bireylerin ortak duygu ve düşünceleri kültürü meydana getirmiş, dilkültür ilişkisi bu şekilde önem arz etmiştir.

Dillerin hemen hepsinde dili konuşan topluluğun kültürüne ait, bazı şartlarda ve durumlarda söylenmesi gelenek olmuş sözler, hislerini somutlaştıran kalıplar, farklı klişeler bulunmaktadır. Şöyle ki; birisiyle karşılaştığımızda, bir yakınımızın bayramını kutlarken, birisinden bir iyilik gördüğümüzde, birisinin cenazesi olduğu durumlarda söylediğimiz sözler buna örnektir. Bu klişeler/kalıplar, aynı dili konuşan insanların birbirleriyle kurdukları ilişkiler hakkında, dolayısıyla da o kişilerin ortak kültürleri ile ilgili bize birçok veri sağlayabilir. Kalıp ifadeler, günlük hayatta iletişim içerisinde bulunulan her an ihtiyaç duyulan, insanlar arası ilişkileri düzenleyen iletişimi olumlu kılan söz gruplarıdır (Özen, 2020, s.2). Bu söz gruplarından alan yazında ön plana çıkan araştırmacılar tarafından daha çok incelenen ve toplumda nispeten bilinirliği fazla olanlar deyim ve atasözleridir. Deyim ve atasözleri dışında tanımı ve sınıflaması nispeten daha güç olan kalıp sözlerin, iletişimi başlatan sürdüren ve bitiren dil öğeleri olarak günlük yaşamımızdaki önemi büyüktür.

Kalıp sözler, belli durumlarda söylenmesi gelenek olmuş sözlere denir (Bilgin, 2006, s.75). Kalıp sözlerle ilgili yapılan bu gibi tanımlar genel olarak dil bilim özelliklerinden ayrı tutulup, kültür ve yaşayışa ait unsurlar dikkate alınarak yapılmıştır. Çotuksöken'e (1994, s.8) göre yapısal anlamda kalıp sözler en az iki sözcükten oluşan, içinde bulunan sözcükleri temel anlamlarını kaybetmeden yeni bir kavramı olguyu, eylemi karşılayan söz gruplarıdır. Kullanım ve kültüre ait özellikleriyle birlikte yapı unsurlarının da üzerinde duran Toklu (1995, s.113-114; 2003, s.109) kalıp sözlerin belirli iletişim durumlarında, daha çok da toplumsal uzlaşıma dayalı durumlarda alışılagelmiş bir biçimde kullanılan kalıplaşmış sözcük yapıları olduğunu vurgular. Wray ve Perkins'e (2000) göre, sürekli veya süreksiz, sözcüklerden veya başka anlamlardan meydana gelen dizi halinde küçük basit oluşumlu veya öyle görünen elemanlar; depo edilmiş ve konu edilmek yerine kullanım sırasında hafizadan tamamen alınmış gramerik yapının inşası veya analizidir. Wood (2002) kalıp sözleri tek bir işlevi olan, duygu aktarımına yardımcı sözlüksel unsurlar olarak değerlendirir. Irujo (1986), Bahns vd. (1986), Hickey (1993) ve Coulmas (1994) ise kalıp sözleri hem anadil hem de yabancı dil öğreniminde günlük hayatı kolaylaştıran dil becerilerini geliştiren farklı cümle yapıları oluşturmaya yardımcı olan temel dil birimleri olarak görür. Özen (2020, s.2) ise kalıp sözlerin iletişimi başlatan sürdüren ve bitiren unsurlar olduğunu vurgular.

Alan yazındaki en geniş tanımıyla Gökdayı (2015, s.71) kalıp sözleri; “önceden belirli bir biçime girip hafızada öylece saklanan söyleneceği sırada yeniden üretilmeyip olduğu gibi hatırlanarak, gerekiyorsa bazı eklemeler veya çıkarmalar yapılarak kullanılan tek bir sözcükten, ardışık veya aralı sözcükler içeren sözcük öbeği ya da tümceden oluşabilen belirli durumlarda söylenmesi toplumca benimsenmiş ve görece bir sıklığa sahip sözler olarak iletişimin kurulmasına devamına ya da sonlandırılmasına yardım eden ve kullanım yerleri çok sınırlı olan kalıplaşmış dil birimleri” olarak değerlendirir. Bu bağlamda Gökdayı (2008, s.101) kalıp sözleri anlam özellikleri yönünden alt kategorilere ayırmıştır:

"Hayır dua ve iyi dilek bildirenler: güle güle oturun, Allah razı olsun, Allah ne muradın varsa versin, mutlu yıllar, doğum günün kutlu olsun, iyi bayramlar; küfür, beddua-ilenç bildirenler: lanet olsun, Allah cezasinı versin, Allah kahretsin, Allah bela(si)nı versin. 
duygusal tepkileri dile getirenler (korku, sevinç, şaşkınlık, acıma, çağrı, buyruk, yasaklama, vb.): güler misin ăglar mısın, Allah aşkına, aklına şaşayım, Allah çarpsın, güleriz ağlanacak halimize; selamlaşma bildirenler: günaydın, iyi akşamlar, iyi sabahlar, selamünaleyküm (dinsel bir yan anlamı söz konusudur), iyi günler, merhaba; ayrllık bildirenler: hoşça kal, görüşmek üzere, iyi yolculuklar, görüşürüz, Allah'a ısmarladık, elveda" gibi (Gökdayl, 2008, s.101).

Gökdayı'nın (2008) sınıflamasından da görüleceği üzere sözlü kültürün güçlü olması dolayısıyla Türkçede kalıplaşmış ifadelerin (atasözü, deyim, ikileme, kalıp söz) pek çok dilden daha zengin olduğu ileri sürülebilir. Kalıp sözlerin hayatın, konuşma dilinin her alanında çok geniş yer bulmasına rağmen Türkçe öğretim programlarında (MEB, 2019) dikkatlerden kaçmış olmasının önemli bir eksiklik olduğu söylenebilir. Öyle ki yeni doğan bireyler ana dilini edinmeye başlamasıyla birlikte kalıp sözleri hafizasına yerleştirir (Özen, 2020, s.2). Bireylerin hafizalarına kodlanan bu kalıplar; ihtiyaç halinde, iletişim kurabilmek için anahtar olacaktır. Bu sebeple bireylerin sağlıklı iletişim kurabilmek için ömür boyu ihtiyaç duyacakları bu kalıpları formal yollarla dramatizasyon ile veya edebi değeri yüksek hikâye roman gibi eserler aracıllğıyla öğrenmelerinin zorunluluğu görülmektedir.

Kalıp sözlerin öğretimi formal yollarla çocuk edebiyatı eserleri temelinde ele alınabilir. Çocuk edebiyatı; gelişme ve yetişme dönemindeki çocukların temel dil becerilerine (anlama ve anlatma), hayal, duygu ve düşünce evrenine seslenen, yaşamını zenginleştiren, onlarda "güzellik" duygusu uyandıran sözlü ve yazılı ürünlerin genel adıdır (Gökçe ve Sis, 2011, s.1926). Türkiye'de çocuk edebiyatı eserleriyle tanınan Gülten Dayığlu'nun hikâyeleri, bireylerin iletişim kurarken hayat boyu ihtiyaç duyacakları kalıp sözlerin kazandırılmasında etkili birer araç olabilir.

\subsection{Araştırmanın Amacı}

$\mathrm{Bu}$ çalışmanın amacı bireylerin hayat boyu ihtiyaç duyacakları kalıp sözlerin kategorik olarak Gülten Dayığlu eserlerinde ne sıklıkta yer aldığını tespit etmektir. Kalıp sözlerin Türkçe ders kitaplarındaki bazı metinlerde bulunmasına karşın Türkçe öğretim programlarında herhangi bir kazanım maddesine yer verilmemiştir (MEB, 2019). Bununla birlikte kalıp sözlerin hayatın her anında ve alanında kullanılıyor olması; kategorik olarak kalıp söz öğretiminin MEB okullarında sistemli bir biçimde edebi eserler aracıllğıyla öğretimini önemli hale getirmektedir. Çalışmada Gökdayı'nın (2008) kalıp sözlerle ilgili yaptığı kategorik düzenleme doğrultusunda Gülten Dayığlu eserlerinin kalıp sözler yönünden incelenmesi hedeflenmektedir. Bu yolla çalışmanın, kalıp sözlerin kategorik olarak öğretimi ile ilgili bir başvuru kaynağı niteliğinde olması beklenmektedir.

\subsection{Araștırmanın Problemi}

Gülten Dayığlu eserlerindeki kalıp söz varlığı kategorik olarak nasıldır?

\subsubsection{Araștırmanin Alt Problemleri}

1. Gülten Dayığlu eserlerinde hayır dua ve iyi dilek bildiren kalıp sözler nelerdir?

2. Gülten Dayığlu eserlerinde küfür beddua ve ilenç bildiren kalıp sözler nelerdir?

3. Gülten dayığlu eserlerinde duygusal tepkileri dile getiren kalıp sözler nelerdir?

Anadolu Üniversitesi Eğitim Fakültesi Dergisi (AUJEF), 6(1), 1-16 
4. Gülten Dayığlu eserlerinde selamlaşma bildiren kalıp sözler nelerdir?

5. Gülten Dayığlu eserlerinde ayrılık bildiren kalıp sözler nelerdir?

6. Gülten Dayığlu eserlerinde batıl inanç bildiren kalıp sözler nelerdir?

7. Gülten Dayığlu eserlerinde konuşanı/dinleyeni yüceltme bildiren kalıp sözler nelerdir?

8. Gülten Dayığlu eserlerinde bir isteği kabul ya da ret bildiren kalıp sözler nelerdir?

9. Gülten Dayığlu eserlerinde dinleyeni eleştirme uyarma ve tehdit bildiren kalıp sözler nelerdir?

10. Gülten Dayığlu eserlerinde töre gelenek ve kültürel değerleri yansıtan kalıp sözler nelerdir?

11. Gülten Dayığlu eserlerinde dini inanç bildiren kalıp sözler nelerdir?

12. Gülten Dayığlu eserlerinde özür dileme bildiren kalıp sözler nelerdir?

13. Gülten Dayığlu eserlerinde sembolik ödüllendirme bildiren kalıp sözler nelerdir?

14. Gülten Dayığlu eserlerinde teşekkür bildiren kalıp sözler nelerdir?

\section{YÖNTEM}

$\mathrm{Bu}$ çalışma nitel araştırma yöntemine dayalı doküman incelemesi modelindedir. Doküman inceleme anlam çıkarmak, ilgili konu hakkında bir anlayış oluşturmak, ampirik bilgi geliştirmek için verilerin incelenmesini ve yorumlanmasını gerektirmektedir (Corbin \& Strauss, 2008).

Araştırma içeriği, yöntemi; sunduğu bilgi, yorum ve sonuçları itibarıyla etik kurul raporuna ihtiyaç duymamaktadır. Araştırmanın her aşaması yayın etiğine uygun gerçekleştirilmiştir.

\subsection{Veri Toplama ve Analizi}

Çalışmada veriler kalıp sözler ile ilgili en kapsamlı çalışmaları gerçekleştiren, kalıp sözleri ayrıntılı olarak kategorilere ayıran Gökdayı'nın (2008) kalıp söz sinıflaması temele alınarak biri araştırmacı tarafından eserlerdeki kalıp sözlerin tespitiyle elde edilmiştir. Veri toplama tamamlandıktan sonra eserlerden elde edilen kalıp sözlerin Gökdayı'nın (2008) sınıflamasına uyup uymadı̆̆ 1 araştırmacı dışında üç alan uzmanınca kontrol edilmiş, bu şekilde güvenirlik sağlanmaya çalışılmıştır. Buna göre ilgili kategoriye uymayan kalıp sözler çıkarılmış veya yanlış kategoriye alındığı görülen kalıp söz ait olduğu kategoriye dâhil edilmiştir. Bu haliyle içerik analizine tabi tutulan verilerin yorumları, araştırmacı ile birlikte üç alan uzmanının görüşleri doğrultusunda düzenlenmiştir. Verilerin toplanması ve analiz sürecinin her bir adımında uzman görüşlerine başvurarak geçerlik ve güvenirlik sağlanmaya çalışılmıştır.

Bulgularda, kalıp sözlerin kategorik olarak eserlerdeki karşılıklarının frekans değerleri bulunmaktadır. Her bir eser için veri toplama ve analiz, ayrı ayrı gerçekleştirilmiştir. 


\section{BULGULAR VE YORUMLARI}

Bu bölümde Gülten Dayığlu eserlerindeki kalıp sözler kategorik olarak verilmiş ve yoruma tabi tutulmuştur. Kalıp sözlerin eserlerdeki sıklık değerleri tablo halinde gösterilmiştir.

\subsection{Alt Problem 1.}

Tablo 1: Eserlerdeki Hayır Dua ve İyi Dilek Bildiren Kalıp Sözler

\begin{tabular}{lcc}
\hline Kalıp Söz & $\begin{array}{c}\text { Yurdumu } \\
\text { Özledim (f) }\end{array}$ & Tuna'dan Uçan Kuş (f) \\
\hline Allah bana sabır versin & 1 & \\
\hline Tanrı seni bunaltmasın & 1 & 2 \\
\hline Tanrı senden razı olsun & 1 & \\
\hline Hayırlı olsun & 2 & 1 \\
\hline $\begin{array}{l}\text { Tanrı seni } \text { anana } \\
\text { bağışlasın }\end{array}$ & 1 & 1 \\
\hline Bayramın kutlu olsun & 1 & 1 \\
\hline Hayırlısıyla & & 1 \\
\hline Her şey gönlünce olsun & & 1 \\
\hline Ömrünüze duacıyım & 1 \\
\hline Allah senden razı olsun & 1 \\
\hline $\begin{array}{l}\text { Allah Halil İbrahim bereketi } \\
\text { versin }\end{array}$ & & \\
\hline Hayırlı günlerde kullan & & \\
\hline Allah bir avazda kurtarsın & & \\
\hline
\end{tabular}

Günlük yaşamımızda hayır dua ve iyi dilek bildiren kalıp sözler iletişimin sürekliliği yönünden önem arz eder. Gülten Dayığlu eserleri de incelendiğinde bu kalıp sözlerin on altı kez kullanıldığı görülmektedir. Yazarın Yurdumu Özledim adlı eserinde "Tanrı" kelimesini kalıp söz içerisinde kullanması dilde öze dönük bir yaklaşım olarak görülmektedir. Ayrıca yakın zamanda doğum yapacak kadınlara iyi dilekte bulunmak için söylenen "Allah bir avazda kurtarsın" kalıp sözü, her ne kadar öğrenci seviyesi için uygun görülmese de, bu kalıp sözün eserde yer almış olması söz varlığı açısından oldukça önemlidir. Genel olarak eserler, hayır dua ve iyi dilek bildiren kalıp sözler yönünden yeterlidir.

\subsection{Alt Problem 2.}

Tablo 2: Eserlerdeki Küfür Beddua ve İlenç Bildiren Kalıp Sözler

\begin{tabular}{lcc}
\hline Kalıp Söz & $\begin{array}{c}\text { Yurdumu } \\
\text { Özledim (f) }\end{array}$ & Tuna'dan Uçan Kuş (f) \\
\hline Gözü kör olası & 1 \\
\hline Allah kahretsin & 2 \\
\hline Defolun & 1 \\
\hline Allah cezanı versin & 2 \\
\hline
\end{tabular}


Eğitim bireyleri istendik yöne sevk etmektir (Erdem, 2005). Öyleyse özellikle eğitim çağındaki bireyler birbirlerine karşı hoşgörü ve anlayışla, sevgiyle yaklaşmalıdır. Bu sebeple küfür beddua ve ilenç bildiren kalıp sözlerin Gülten Dayığlu'nun Yurdumu Özledim adlı eserinde altı kez bulunması, Tuna'dan Uçan Kuş adlı eserinde hiç yer almaması yerinde görülmektedir. Eserler, öğrenci gelişimleri de düşünüldüğünde küfür beddua ve ilenç bildiren kalıp sözlerin oldukça az bulunması yönünden uygundur.

\subsection{Alt Problem 3.}

Tablo 3: Eserlerde Duygusal Tepkileri Dile Getiren Kalıp Sözler

\begin{tabular}{lcc}
\hline Kalıp Söz & $\begin{array}{c}\text { Yurdumu } \\
\text { Özledim (f) }\end{array}$ & Tuna'dan Uçan Kuş (f) \\
\hline Kim bilir? & 3 \\
\hline Yaşasın! & 3 \\
\hline N'olursun & 5 \\
\hline Aman! & 2 & \\
\hline Davranın & 1 \\
\hline Yetişin! & 1 & \\
\hline Eyvah! & 1 & 1 \\
\hline Bağlasan durmam & 1 & 1 \\
\hline Ne olursa olsun & 1 & 1 \\
\hline Nedir senden çektiğim? & 1 & 1 \\
\hline Lütfen & 3 & 1 \\
\hline Bir bu eksikti! & & \\
\hline Allah bilir & & 1 \\
\hline Hayrola? & & \\
\hline Allah allah? & & \\
\hline Ne umdum ne buldum & & \\
\hline
\end{tabular}

Eserler incelendiğinde duygusal tepkileri dile getiren yirmi yedi kalıp söz tespit edilmiştir. Bu, eser kahramanlarının çocuk olmasından, dolayısıyla yeni karşılaştığı durumlara uyum sağlamaya çalışırken duygusal tepkilerini sıklıkla gösterme gayretinden ileri gelmektedir. Yazarın hitap ettiği öncelikli kitlenin de çocuk olduğu bilindiğine göre eserlerde duygusal tepkileri dile getiren kalıp söz varlığ1 yeterli görülmektedir. 


\subsection{Alt Problem 4.}

Tablo 4: Eserlerdeki Selamlaşma Bildiren Kalıp Sözler

\begin{tabular}{lcc}
\hline Kalıp Söz & $\begin{array}{c}\text { Yurdumu } \\
\text { Özledim (f) }\end{array}$ & Tuna'dan Uçan Kuş (f) \\
\hline Selam söyle & 1 & 1 \\
\hline N'oldun? & 1 & \\
\hline Hoş geldiniz & 1 & \\
\hline Günaydın & 2 & \\
\hline İyi akşamlar & 1 \\
\hline
\end{tabular}

Selamlaşma bildiren kalıp sözlerin, iletişimi başlatma ve bitirme yönünden görevi oldukça önemlidir. Eserler incelendiğinde selamlaşma bildiren kalıp sözlerin yedi defa kullanılmış olması yetersiz görülmektedir. Özellikle sosyalleşmeye ve iletişim becerilerini inşa etmeye başlayan ilköğretim öğrencilerinin en çok ihtiyaç duyacağı kalıp sözlerin selamlaşma bildirenler olduğu düşünüldügünde eserlerde bu sınıftaki kalıp sözlerin yetersiz oluşu, eserleri bu yönden eksik birakmaktadir.

\subsection{Alt Problem 5.}

İletişimi bir süreç halinde düzenli yürütebilmek için kalıp sözlerin uygun başlangıç ve bitiş ifadelerini seçmek gerekir. Eserdeki ayrılık bildiren kalıp sözler incelendiğinde üç kez kullanıldığı tespit edilmiştir. Bu sınıftaki kalıp söz varlığının eserlerde yeterli düzeyde temsil edilmediği görülmektedir.

Tablo 5: Eserlerdeki Ayrllık Bildiren Kalıp Sözler

\begin{tabular}{lcc}
\hline Kalıp Söz & $\begin{array}{c}\text { Yurdumu } \\
\text { Özledim (f) }\end{array}$ & Tuna'dan Uçan Kuş (f) \\
\hline Yolcu yolunda gerek & 1 & \\
\hline Hoşçakal & 1 & 1 \\
\hline Yolun açık olsun & & \\
\hline
\end{tabular}

\subsection{Alt Problem 6.}

Eserlerde batıl inanç bildiren kalıp söz bulunmamaktadır. Okuyucu kitlenin gelişimsel özellikleri göz önünde bulundurulduğunda batıl inanışlara ilişkin kalıp söz kullanımının olmamasının doğru bir yazar tutumu olduğu söylenebilir. 


\subsection{Alt Problem 7.}

Tablo 6: Eserlerdeki Konuşanı/Dinleyeni Yüceltme Bildiren Kalıp Sözler

\begin{tabular}{lcc}
\hline Kalıp Söz & $\begin{array}{c}\text { Yurdumu } \\
\text { Özledim (f) }\end{array}$ & Tuna'dan Uçan Kuş (f) \\
\hline Aferin & 1 \\
\hline Çok yaşa & 1 & \\
\hline
\end{tabular}

Eğitimde istendik davranışların devamı ve iletişimin olumlu sürdürülebilmesi için bireylerin söz ve davranışlarının uygun bir ifadeyle pekiştirilmesi gerekebilir. Eserler incelendiğinde konuşanı/dinleyeni yücelten kalıp sözlere oldukça az yer verildiği görülmektedir. Bu açıdan eserler, konuşanı dinleyeni yücelten kalıp sözler yönünden yetersizdir.

\subsection{Alt Problem 8.}

Tablo 7: Eserlerdeki Bir İsteği Kabul ya da Ret Bildiren Kalıp Sözler

\begin{tabular}{lcc}
\hline Kalıp Söz & $\begin{array}{c}\text { Yurdumu } \\
\text { Özledim (f) }\end{array}$ & Tuna'dan Uçan Kuş (f) \\
\hline Bana ne & 1 & 1 \\
\hline Elbette & 5 & \\
\hline Öyle deme & 1 & 1 \\
\hline Başüstüne & 2 & \\
\hline
\end{tabular}

Eserler incelendiğinde bir isteği kabul ya da ret bildiren kalıp sözlerin on bir kez yer aldığ görülmektedir. Yurdumu Özledim adlı eserde "elbette" kalıp sözünün sık kullanılmış olması, ana kahraman Atıl'ın çevresini tanıma çabası içerisinde sıklıkla onaylanmak istemesinden kaynaklanmaktadır. Yurdumu Özledim adlı eserin bir isteği kabul ya da ret bildiren kalıp sözler yönünden yeterli olduğu görülürken, Tuna'dan Uçan Kuş adlı eserin bu yönden yetersiz olduğu tespit edilmiştir.

\subsection{Alt Problem 9.}

Tablo 8: Eserlerdeki Dinleyeni Eleştirme Uyarma Tehdit Bildiren Kalıp Sözler

\begin{tabular}{lcc}
\hline Kalıp Söz & $\begin{array}{c}\text { Yurdumu } \\
\text { Özledim (f) }\end{array}$ & Tuna'dan Uçan Kuş (f) \\
\hline Her neyse & 1 \\
\hline Günahım senin boynuna & 1 \\
\hline Düş önüme & 1 \\
\hline Sakın ola & 5 \\
\hline Bu sana ders olsun & 1 \\
\hline Rica ediyorum & & 1 \\
\hline
\end{tabular}


Eserler dinleyeni eleştirme uyarma tehdit bildiren kalıp sözler yönünden incelendiğinde bu kalıp sözlerin on kez yer aldığı tespit edilmiştir. "Sakın ola" kalıp sözünün Yurdumu Özledim adlı eserde beş kez bulunması, hikâye kahramanı Atıl'ın Almanya macerası sırasında yeni çevresine uyum sağlamaya çalışırken dikkat etmesi gereken hususların büyükleri tarafından sıklıkla hatırlatılması ile açıklanabilir. Eleştirme uyarma tehdit bildiren kalıp sözler yönünden Yurdumu Özledim adlı eserin yeterli olduğu görülmektedir. Tuna'dan Uçan Kuş adlı eser ise bu kategorideki kalıp sözler yönünden yetersizdir.

\subsection{Alt Problem 10.}

Tablo 9: Eserlerdeki Töre Gelenek ve Kültürel Değerleri Yansitan Kalıp Sözler

\begin{tabular}{lcc}
\hline Kalıp Söz & $\begin{array}{c}\text { Yurdumu } \\
\text { Özledim (f) }\end{array}$ & Tuna'dan Uçan Kuş (f) \\
\hline Feda olsun & 1 \\
\hline
\end{tabular}

Dil kültürün taşıyıcısıdır (Aksan, 2007). Kültürün izlerini dilde görmek mümkündür. Bu durum kalıp sözlere de yansımıştır. Türkçe kalıp sözler yönünden Türk kültürünü temsil edebilmektedir. Eserler incelendiğinde ise töre gelenek ve kültürel değerlere ait kalıp sözlerin eserlerde oldukça yetersiz kaldığ görülmektedir.

\subsection{Alt Problem 11.}

Tablo 10: Eserlerdeki Dini Inanç Bildiren Kalıp Sözler

\begin{tabular}{lcc}
\hline Kalıp Söz & $\begin{array}{c}\text { Yurdumu } \\
\text { Özledim (f) }\end{array}$ & Tuna'dan Uçan Kuş (f) \\
\hline Allah'a şükür & 1 & 2 \\
\hline Allah rızası için & 1 & 1 \\
\hline Çok şükür & 3 & 1 \\
\hline Allah'ın izniyle & 1 & \\
\hline İnşallah & 5 & 2 \\
\hline Allah vere & 1 & 1 \\
\hline Bismillah & & 1 \\
\hline Hayırdır inşallah & & 1 \\
\hline Hakkını helal et & & \\
\hline Tövbe bismillah & & 1 \\
\hline
\end{tabular}

Türkçe, dini inanç bildiren kalıp sözler yönünden zengindir (Gökday1, 2008). Eserler incelendiğinde de bu durum görülmektedir. Yirmi bir kez dini inanç bildiren kalıp sözlerin kullanıldığ 1 eserler bu kategori yönünden yeterlidir. 


\subsection{Alt Problem 12.}

Tablo 11: Eserlerdeki özür bildiren kalıp sözler

\begin{tabular}{lcc}
\hline Kalıp Söz & $\begin{array}{c}\text { Yurdumu } \\
\text { Özledim (f) }\end{array}$ & Tuna'dan Uçan Kuş (f) \\
\hline Özür dilerim & 1 & 1 \\
\hline Kusura bakma & 5 & \\
\hline Bağıșlayın & 1 & \\
\hline
\end{tabular}

Özür dilemek ve bunu uygun bir biçimde dile getirmek sosyalleşme çabası içerisindeki bireyler için önemlidir. Eserler özür dileme bildiren kalıp sözler yönünden incelendiğinde oldukça yetersiz olduğu görülmektedir. Bu durumun eserlerdeki olay kurgusu ile ilgili olduğu, kahramanların içerisinde bulunduğu durumların özür dileme bildiren kalıp söz kullanmalarını çok az gerektirmesinden kaynaklandığg düşünülmektedir.

\subsection{Alt Problem 13.}

Tablo 12: Eserlerdeki Sembolik Ödüllendirme Bildiren Kalıp Sözler

\begin{tabular}{lcc}
\hline Kalıp Söz & $\begin{array}{c}\text { Yurdumu Özledim } \\
\text { (f) }\end{array}$ & $\begin{array}{c}\text { Tuna'dan Uçan } \\
\text { Kuş (f) }\end{array}$ \\
\hline Kutlu olsun & 1 & \\
\hline
\end{tabular}

Eğitim çağındaki bireylerde istendik yönde davranış değişikliği gerçekleştirebilmek için ödül, önemli bir yer tutar. Ödül kavramı kalıp sözler kapsamında da değerlendirilmektedir. Bu yönden eserler incelendiğinde sembolik ödüllendirme bildiren kalıp sözlerin yetersiz olduğu tespit edilmiştir.

\subsection{Alt Problem 14.}

Tablo 13: Eserlerdeki Teşekkür Bildiren Kalıp Sözler

\begin{tabular}{lcc}
\hline Kalıp Söz & $\begin{array}{c}\text { Yurdumu } \\
\text { Özledim (f) }\end{array}$ & Tuna'dan Uçan Kuş (f) \\
\hline Sağ olun & 1 & 1 \\
\hline Ellerine sağlık & 1 \\
\hline Elhamdülillah & 1 \\
\hline Allah'a şükürler olsun & \\
\hline
\end{tabular}

Eğitimin ilk dönemlerindeki bireyler için 'teşekkür etme' önemli bir davranıştır. 'Teşekkür etme' bireylerin kişiler arası ilişkilerini düzenlemelerindeki önemli basamaklardan biridir. Öğrenciler diğer kalıp sözleri olduğu gibi teşekkür etmeyi bildiren kalıp sözleri de çevreleriyle ilişkileri sırasında öğrenirler. Özür dilemeyi gerektirecek gerçek ortam bulunmadığında öğrenme, eserlerdeki diyaloglar yoluyla gerçekleşebilir. Ancak araştırmaya konu eserlerin teşekkür bildiren kalıp sözler yönünden yetersiz olduğu görülmüştür. 


\section{TARTIŞMA, SONUÇ ve ÖNERILER}

Kalıp sözler iletişimi başlatan sürdüren ve bitiren dolayısıyla iletişimi düzenleyen dil birimleridir. Bireyler bu kalıpları doğdukları andan itibaren uygun durumda kullanmak üzere hafizalarında kodlarlar.

Kalıp sözlerin insanın yaşamın her döneminde ihtiyaç duyduğu dil birimleri olduğu bilinmektedir (Gökdayı, 2008; Sis ve Gökçe 2009; Uçgun ve Çetinkaya, 2016; Özkan, 2012; Özen, 2020). Buna karşın ana dili Türkçe olan bireyler için kalıp sözlere MEB Türkçe müfredatında (2019) birer kazanım olarak yer verilmemiştir. Bununla birlikte kalıp sözler sınıflandırılıp uygulamaya dönük olarak edebi değeri yüksek eserler yoluyla öğretilmelidir. Bu sebeple çocuk edebiyatının önemli yazarlarından olan roman ve hikâye alanında birçok ödül almış Türkiye'de yapılan anketlerde en çok okunan yazar seçilen 2008 yılında Türkiye Kütüphaneler Birliği tarafından internet ortamında yapılan araştırmalar sonucu en başarılı çocuk kitapları yazarı birinciliği bulunan Gülten Dayığlu'nun eserleri bu açıdan incelenebilir. Alan yazın tarandığında Sis ve Gökçe'nin (2009) Gülten Dayığlu eserlerindeki kalıp söz varlığını incelediği, ancak tespit edilen kalıp sözlerin hangi kategoriye ait olduğunu belirtmedikleri görülmüştür. Benzer şekilde Uçgun ve Çetinkaya (2016) Gülten Dayığlu eserlerindeki deyimlerin öğrenciler tarafından tanınırlık düzeyini tespit etmiştir. Buna göre Gülten Dayığlu öyküleri, deyim gibi dil birimlerinin kazandırılmasında etkilidir.

$\mathrm{Bu}$ çalışma ise Gülten Dayığlu eserlerinde yer alan kalıp sözlerin sıklıkla hangi kategorilerde bulunduğunu ortaya koyan nitel bir araştırmadır. Kalıp sözlerin kategorilere göre verilmesi farklı sınıf düzeylerinde öğrenim gören öğrenciler için daha uygun görülmektedir. Yazarın araştırmaya konu eserleri olan Yurdumu Özledim'de kırk altı ve Tuna'dan Uçan Kuş’ta yirmi yedi adet olmak üzere toplam yetmiş üç kalıp sözün yüz on iki kez kullanıldığı tespit edilmiştir. Kategorik olarak kalıp sözlerin eserlerdeki kullanımları incelendiğinde "hayır dua ve iyi dilek bildiren" kalıp sözlerin eserlerde yeterli olduğu görülmektedir. Hayır dua bildiren "Tanrı senden razı olsun", "Tanrı seni bunaltması" gibi kalıp sözlerde kullanılan Tanrı kelimesi yazarın dilde öze dönük bir tutum tercih ettiğini de ortaya koymaktadır. "Küfür beddua ilenç bildiren" kalıp sözlere eserlerde çok az yer verildiği görülmektedir. Bu durumun, eserlerin hitap ettiği çocukların gelişimsel dönemleri göz önünde bulundurulduğunda kabul edilebilir olduğu düşünülmektedir. Çocuklar duygularını açıkça dile getirebilirler. "Duygusal tepkileri dile getiren" kalıp sözler incelendiğinde eserlerin bu kalıp sözler yönünden yeterli olduğu görülmüştür. Kalıp sözlerin iletişimi başlatma ve bitirmede önemli bir yeri vardır (Özen, 2020). Eserler incelendiğinde ise "selamlaşma bildiren" ve "ayrılık bildiren" kalıp sözlerin yetersiz olduğu tespit edilmiştir. Eğitimin amacının bireylerde istendik davranış değiştirme olduğu bilinmektedir. Bu doğrultuda "batıl inanç bildiren" kalıp sözlerin eserlerde bulunmaması yerinde görülmektedir. İletişimde bir diğer önemli husus muhatabın sözlerini etkili biçimde onaylama ve reddetmedir. Eserler incelendiğinde "konuşanı, dinleyeni yüceltme bildiren" ve "dinleyeni eleştirme uyarma tehdit bildiren" kalıp sözlerin Yurdumu Özledim adlı eserde yeterli, Tuna'dan Uçan Kuş adlı eserde yetersiz olduğu görülmektedir.

Aksan (2007) dil ile kültür arasında sıkı bir ilişki olduğunu vurgular. Aksan (2007)'a göre dil kültürün gelecek kuşaklara taşır. Bu yönüyle eserler ele alındığında "töre gelenek ve kültürel değerleri yansitan kalıp sözlerin yetersizliği göze çarpar. Bununla birlikte eserlerin her ikisinde de karakterlerin yabancı kültüre uyum sağlamaya çalıştığı düşünüldüğünde "dini inanç bildiren" kalıp sözler yönünden eserlerin zenginliği görülmektedir. İletişimin devamlılığını sağlamada özür dileme, teşekkür etme, söylenileni/davranışı tasdikleme önemlidir. Buna rağmen eserler "özür bildiren”, sembolik ödüllendirme bildiren" ve "teşekkür bildiren" kalıp sözler yönünden oldukça yetersizdir. 
Genel bir bakışla eserlerin yoğun olarak 'hayır dua ve iyi dilek bildiren', 'duygusal tepkileri dile getiren' ve 'dini inanç bildiren' kalıp söz kategorilerine dağılımı dikkat çekmektedir. Hikâyelerdeki olayların milli ve manevi kültür özellikleri etrafında kurgulanmış olması yazarın bu kategorilerdeki kalıp sözleri daha çok tercih etmesine yol açmış olabilir. Özellikle bu kategorilerde yer alan kalıp söz tercihlerinin metin bağlamları içerisinde uygun olarak verilmiş olması öğrencilerin kalıp sözleri daha etkili kodlamalarına ve uygun durumda kullanmalarına yardımcı olacaktır.

Sonuç olarak Gülten Dayığlu'nun 'Yurdumu Özledim' adlı eseri 'hayır dua ve iyi dilek bildiren', 'duygusal tepkileri dile getiren' ve 'dini inanç bildiren' kalıp sözlerin varlığı yönünden yeterlidir. 'Tuna'dan Uçan Kuş' adlı eserin ise kalıp sözlerin sıklık değerleri göz önünde bulundurulduğunda 'Yurdumu Özledim' adlı esere göre nispeten yetersiz olduğu görülmektedir. Ancak her iki eserin de ilköğretim çağındaki çocukların kalıp söz dağarcıklarını kategorik olarak geliştirmeleri yönünden etkili olacağı düşünülmektedir. Elde dilen bulguların sonuçları 1şı̆̆ında araştırmacı ve uygulayıcılara yönelik birtakım öneri sunmak yerinde görülmektedir:

Eserlerin kalıp sözlerin yoğun olarak bulunan bölümlerine gerekli yazınsal düzenlemelerin ardından her kademedeki Türkçe ders kitaplarında metin olarak yer verilebilir. Uygulayıcılar kalıp sözlerle ilgili ya da Türkçe müfredatı (2019) "Erdemler" ve "İletişim” temaları altında Gülten Dayığlu'nun araştırmaya konu eserlerinden faydalanabilir. Araştırmaya konu eserlerin dilinin sade açık anlaşılır olması dolayısıyla yabancı dil olarak Türkçe öğretiminde de uygulayıcılar açısından eserler kalıp sözler yönünden öğretimi çeşitlendirmek adına kaynak teşkil edebilir. Benzer şekilde farklı yazarların öykü ve romanları da kategorik olarak kalıp söz varlığı yönünden incelenebilir. 


\section{KAYNAKLAR}

Aksan, D. (2007). Her yönüyle dil ana çizgileriyle dilbilim (2. bask1). Ankara: Türk Dil Kurumu.

Bahns, J., Burmeister, H., \& Vogel, T. (1986). The pragmatics of formulas in L2 learner speech: Use and development. Journal of Pragmatics, 10, 693-723.

Bilgin, M. (2006). Anlamdan anlatıma Türkçemiz Ankara: Anı Yayıncılık.

Corbin, J. \& Strauss, A. (2008). Basics of qualitative research: Techniques and procedures for developing grounded theory. Thousand Oaks: Sage.

Coulmas, F. (1994). Formulaic language. In: Asher, R.E. (Ed.), Encyclopedia of Language and Linguistics. Pergamon, Oxford, pp. 1292-1293.

Çotuksöken, Y. (1994). Deyimlerimiz. İstanbul: Özgül Yayınevi.

Dayığlu, G. (2002). Yurdumu Özledim. İstanbul: Altın Kitaplar.

Dayığlu, G. (2002). Tuna'dan Uçan Kuş. İstanbul: Altın Kitaplar.

Erdem, A. R. (2005). Etkili ve verimli (nitelikli) eğitim. Anı Yayıncılık.

Gökdayı, H . (2008). Türkçede Kalıp Sözler. Bilig , (44) , 89-110.

Gökdayı, H. (2015). Türkçede kalıp sözler. İstanbul: Kriter Basım Yayın Dağıtım.

Hickey, T. (1993). Identifying formulas in first language acquisition. Journal of Child Language, 20, 27-41.

Irujo, S. (1986). A piece of cake: learning and teaching idioms. ELT Journal, 40 (3), 236-242.

Milli Eğitim Bakanlı̆̆ı, MEB (2019). Türkçe Dersi Öğretim Programı, Ankara.

Özen, Ş. (2020). 5. sınıf ögrencilerinin kalıp sözleri tanıma ve yazılı anlatımda kullanma durumları (Manisa örneği). (Yüksek lisans tezi), YÖK Tez Merkezi, 638181

Özkan, E. (2012). İlköğretim 8. sınıf Türkçe ders kitaplarında öğrencilere kazandırllması hedeflenen sözcüklerin öğretimi ve iç sözlük ilişkisi. (Yüksek lisans tezi), YÖK Tez Merkezi, 313165

Sis, N., Gökçe, B. (2009). Gülten Dayığlu'nun Çocuk Öykülerinde Yansımalar ve Kalıp Sözler. Turkish Studies/Türkoloji Araştırmaları Dergisi , 4(3), 1975-1989.

Toklu, M. O. (1995). Türkçe ve Almancada Kalıp Sözler. DTCF Batı Dilleri ve Edebiyatları Araştırma Enstitüsü Dergisi, 3, 113-140

Toklu, M. O. (2003). Şiir dili ve çevirisi. Ankara: Akçağ Yayınları.

Uçgun, D , Çetinkaya, G . (2016). Gülten Dayığlu'nun öykülerindeki deyimlerin tanınırlık ve saydamlık dereceleri bakımından incelenmesi. Milli Eğitim Dergisi , 210 , 521-537.

Wood, D. (2002). Formulaic language in thought and word: Vygotskian perspectives. Cahiers Linguistiques $d$ Ottawa, 29-48.

Wray, A., Perkins, M. R. (2000). The functions of formulaic language: An integrated model. Language and Communication, 1-28.

\section{Internet Kaynakları}

http://www.gultendayioglu.com/oduller (Erişim tarihi: 24.07.2021) 


\section{EXTENDED ABSTRACT}

Almost all of the languages spoken on earth have words or different stereotypes that belong to the culture of the language-speaking community, which have become a tradition to say in situations. For example, when we meet someone, when we celebrate the holiday of a relative, when we see a favor from someone, the words we say when someone has a funeral are examples of this. These stereotypes can provide us with a lot of data about the relationships that people who speak the same language establish with each other, hence the common cultures of those people. Formulaic words are groups of words that are needed at every moment in communication in everyday life, which make communication positive and regulate relationships (Özen, 2020, p.2). Among these groups of words are idioms and proverbs that come to the fore in the literature, which are studied and have relatively high awareness in society. Apart from idioms and proverbs, formulaic words, which are relatively more difficult to define and classify, are of great importance in our daily lives as language elements that start and end communication.

Formulaic words are called words that have become a tradition to be said in certain situations (Bilgin, 2006:75). Such definitions related to formulaic words are generally separated from language science characteristics and made on the axis of culture and life characteristics. In addition, some definitions take into account the usage areas and cultural characteristics of formulaic words (Çotuksöken, 1994, p.8; Toklu, 1995, p.113-114, 2003, p.109; Wray and Perkins, 2000; Wood, 2002; Özen, 2020, p.2), while formulaic words emphasize that they are the elements that start and end communication. Gökday1 with the widest definition in literature $(2015$, p.71) states "stereotyped language units that help to continue or end communication as words that have been adopted by society and have a relative frequency, and whose use is very limited.“. In this context, Gökday1 (2008, p. 101) divided the words into subcategories in terms of their meaning properties. These are; "those that say prayers and good wishes, those that report blasphemy, those that express emotional reactions, those that report greetings, those that report separation, those that report apologies, those that express thanks" etc.

As can be seen in the classification of Gökday1 (2008), it can be suggested that the Turkish language is richer than many languages in terms of formulaic words due to the strong oral culture. However, when the MoNE (2019) Turkish language curriculum is examined, the absence of any acquisition clause related to formulaic words remains a deficiency. Since it is known that individuals begin to acquire formulaic words at the moment they are born, formulaic words can be categorized according to their usage areas and acquired by individuals in formal means. For this purpose, works of high literary value should be used as sources. It is necessary to examine the works of Gülten Dayioğlu, who is successful in the field of children's literature in Turkey, in this direction.

When the literature was examined, it was seen that Sis and Gökçe (2009) examined the presence of formulaic words in Gülten Dayığlu's works, but they did not indicate to which category the detected formulaic words belong. Similarly, Uçgun and Çetinkaya (2016) determined the level of recognition of the idioms in Gülten Dayığlu's works by students. Accordingly, Gülten Dayığlu stories are effective in teaching language units such as idioms.

In this study, the works of Gülten Dayioğlu were categorically examined in terms of the existence of formulaic words. A Turkish teacher and a Turkish education department lecturer created Gülten Dayioğlu's works "Yurdumu Özledim" and "Tuna' dan Uçan Kuş" with the joint proposal of the expert who took the sample of the research. The research was designed by descriptive model, and the data were obtained through document examination. The frequency value of each finding examined by 
content analysis is presented in a table. Expert opinions were consulted in obtaining and interpreting the data. Gülten Dayioğlu found that the words in his works are heavily in the categories of 'prayer and good wishes', 'emotional reactions' and 'religious faith'. The fact that the author did not include 'superstitious' words in both works is seen as a positive attitude when considering the developmental characteristics of children who are interlocutors. However, the works were found to be insufficient in terms of 'parting, glorifying the speaker/listener', 'apologizing' and 'symbolic rewarding'. Considering the frequency values, it is seen that the work named "Yurdumu Özledim" is relatively sufficient compared to the work named "Tuna'dan Uçan Kuş".

As a result, it is believed that the works of Gülten Dayioğlu will be effective in terms of developing the vocabulary of children of primary school age. Similarly, stories and novels by different authors can also be categorically examined in terms of the presence of formulaic words. 